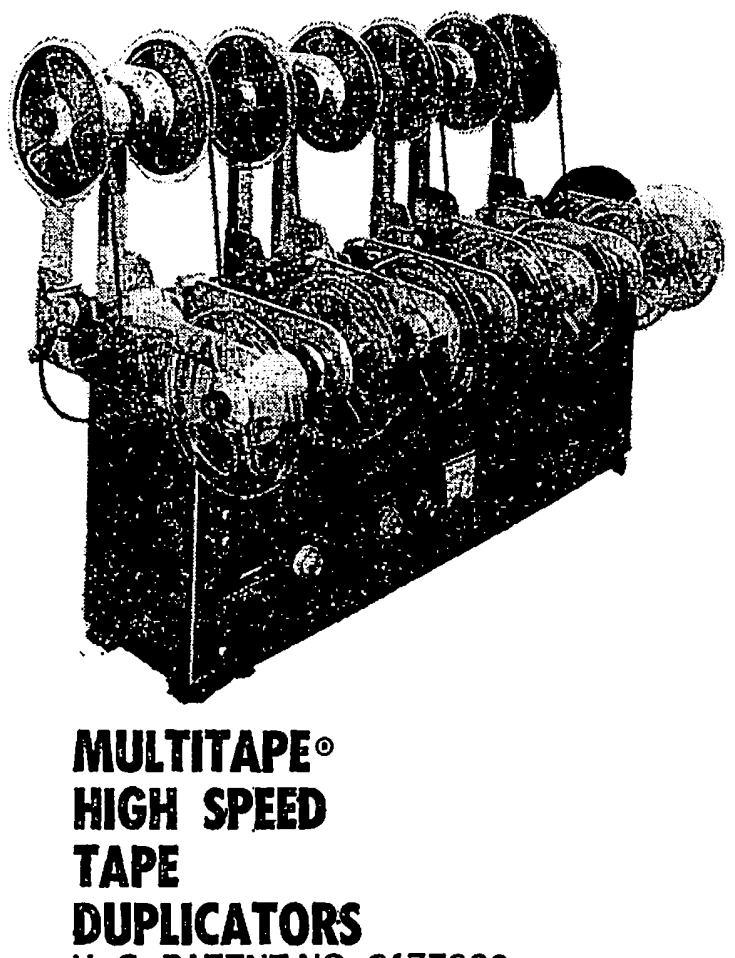

U. S. PATENT NO. 3177299

... make high fidelity copies of your master tapes quickly, easily and economically. MUL. TTAPE models are available to produce as many as six monaural or stereo tape copies in just six minutes-quantity copies at a rate of sixty an hour. Maintenance is minimal. All-solid-state electronics give cool, long-lived operation-and no tubes to replace. A specially designed torque motor means no clutches to adjust, no belts to replace. MULTITAPE units have proven themselves for more than a decade in leading universities and educational systems throughout the United States and foreign countries. They qualify for purchase under N. D. E. A. Write today for details and specifications on this unique, money-saving equipment.

\title{
MANUFACTURED AND SOLD
} EXCLUSTVELT BY

RAWDON SMITH ASSOCIATES, INC. Corporate Offices

1735-20th Street, N. W., Washington, D. C. 


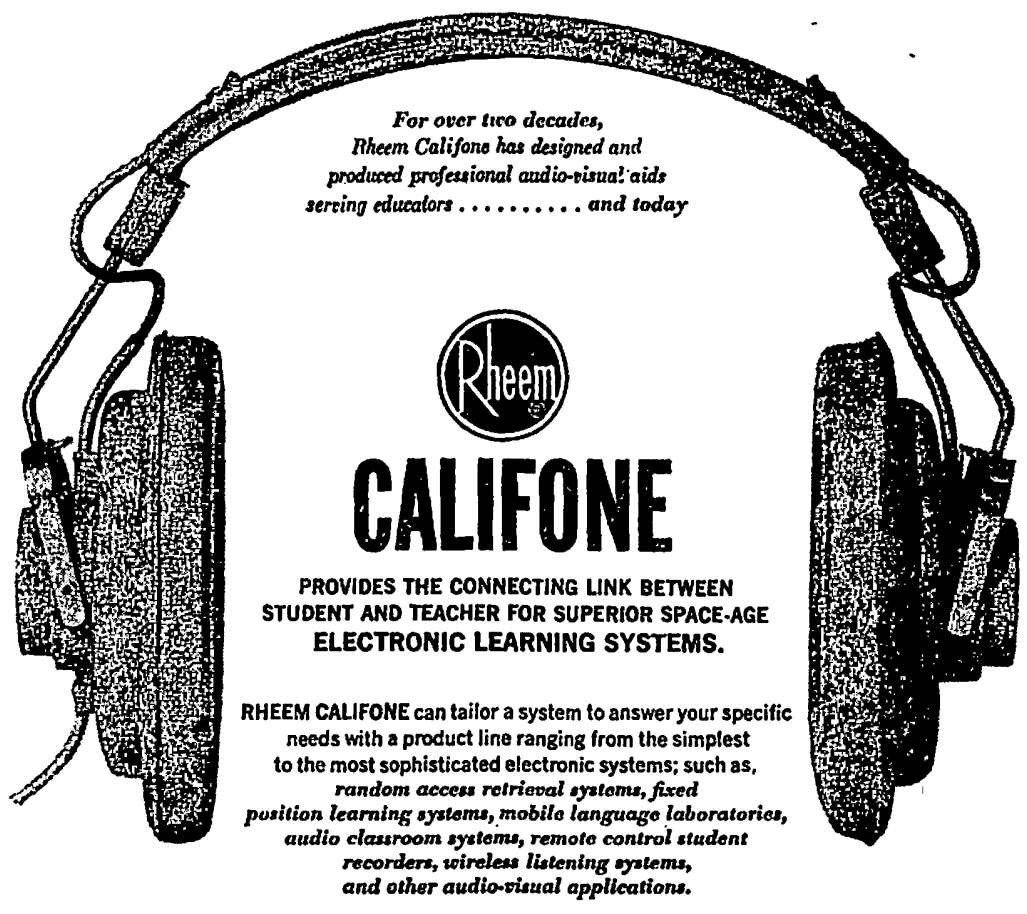

If you are planning a system, put our technical capability to work for you
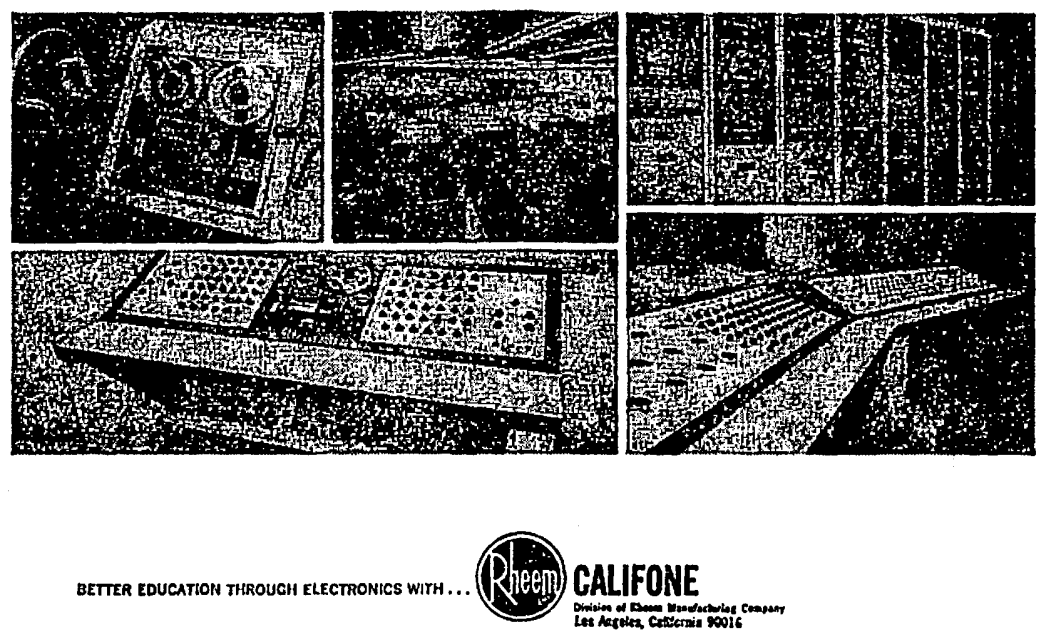


\section{"For a reason similar to why the use of a common \\ drinking cup was given up decades ago-the conimon use of unsanitized headsets should not be permitted ..."}

NOW... FOR .THE LANGUAGE LABORATORY: THE AUTOMATIC GERMICIDAL VAULT THAT COMPLETELY STERILIZES HEADSETS IN JUST FIVE MINUTES-THAT MEANS: NO SPRAYS-NO LIQUIDS-NO WIPING.

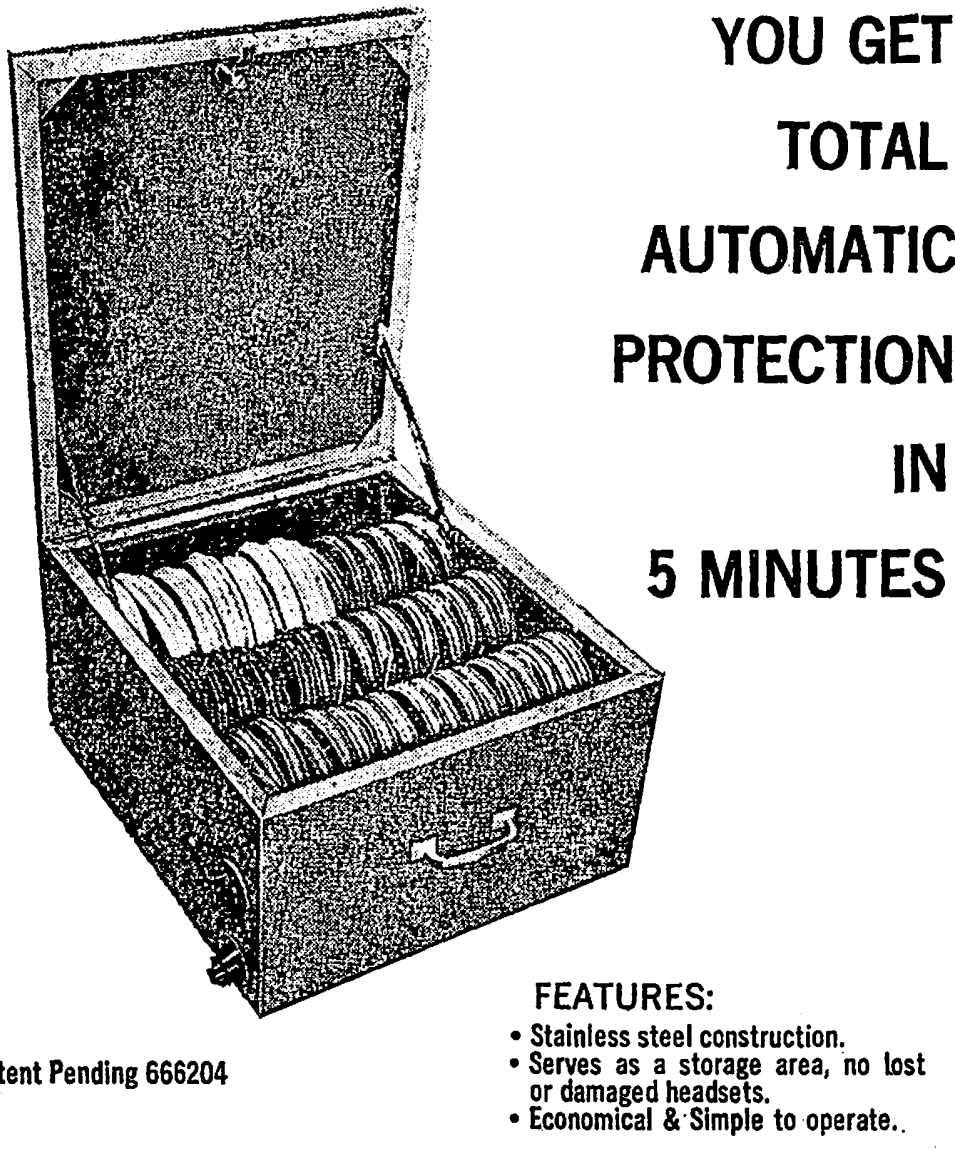

Patent Pending 666204

- Stainless steel construction.

- Serves as a storage area, no lost or damaged headsets.

- Economical \&.Simple to operate.

\section{Micas MICRO PREGISION CORP.} $55-9$ th street Brooklyn N:Y 1 1 215/212.499.7556 


\section{We Invite You}

to examine our programmed course in French pronunciation with Work Books and Answer Sheets.

\section{KEYS TO PRONUNCIATION AND THE WRITTEN WORD.}

Containing practice material reinforcing classroom instruction for self help

-ideal for the Language Laboratory-

Send for Sampler on your official stationery.

Teaching Audials and Visuals, Inc.

250 West 57th St., New York, N. Y. 10019

Producers of teaching materials for French and Spanish on all levels.

FREe catalogue ON REQUEST.

\section{MEMBERSHIP APPLICATION for $\mathbf{1 9 6 7 . 6 8}$}

Check whether this is a (....) Renewal or a (....) New Member

Position

Name:

Or Title:

Name of (High School) (University) :

Circle one of the above

Address to which Newsletter is to be sent:

Address :

City :

State

Zip Code:

(...) My school is paying the dues for NALLD membership; send INVOICE to:

Check for which type of membership you are applying :

(....) Regular Voting Member (USA so States)

(...) Regular Voting Member (Foreign \& Canadian)

$\$ 3.50$

(....) Regular Voting Member (Foreign desiring Air Mail)

$\$ 4.50$

(....) Student, Non-Voting Member

$\$ 2.00$

Membership runs from October to October. Please complete the above form, and teturn the ENTIRB SHEET to :

Sister M. Timona, NAILD Treasurer

Mount Mary College

2900 North Menomonce River Parkway

Milwaukee, Wisconsin 53222 